\title{
COMMISSION 42: CLOSE BINARY STARS
}

\section{(ETOILES DOUBLES SERREES)}

\author{
PRESIDENT: Paula Szkody \\ VICE-PRESIDENT: Alvaro Giménez \\ ORGANIZING COMMITTEE: E.F. Guinan, L. Bianchi, H. Drechsel, \\ D. Gies, Y-W. Kang, J. Linsky, M. Livio, N. Morrell, V. Niemela, Y. Osaki, \\ S. Rucinski, C. Sterken \& J.H. Wood
}

\section{Introduction}

Commission 42 (Close Binaries; web site www.astro.washington.edu/szkody/c42/), held one business session on 15 July at the XXVth General Assembly in Sydney. Science sessions were held together with Commission 27 (Variable Stars) during three Division $\mathrm{V}$ sessions on 22 July. This was purposely done to stimulate interaction among the two commissions within the division, and was so successful this practice is planned to continue at the next General Assembly. Finally, the Working Group on Accretion Physics (WGAP) sponsored by C42 held its two sessions on 21 July as an extension of Joint Discussion 9 (Astrotomography). The Commission appreciates the help of Hans Rickman, General Secretary, in arranging the above session times and meeting rooms. This report summarizes only the business meeting and the actions from the WGAP. The title and authors of the science talks are given in the Division $\mathrm{V}$ proceedings and the WGAP talks will appear in a special issue 325 of Astronomische Nachrichten, edited by Axel Schwope.

\section{Commission Composition Changes}

The recent election results provided the following changes for C42 officers and organizing committee members for 2003-2006. Alvaro Giménez (Spain) will be President, with Slavek Rucinski (Canada) as Vice President. On the OC, Ed Guinan (former President, USA), Luciana Bianchi (USA), Virpi Niemela (Argentina), Yoji Osaki (Japan), Chris Sterken (Belgium) and Janet Wood (UK) have completed their terms and we thank them for their service and help during the last 3-6 years. Doug Gies (USA), Young-Woon Kang (Korea), Jeff Linsky (USA), Mario Livio (USA), Nidia Morrell (Argentina) remain for a second term, while we welcome Ron Hilditch (Scotland), Birgitta Nordstrom (Denmark), Ignasi Ribas (Spain), Ed Sion (USA) and Sonja. Vrielman (Germany) as new members of the OC. The two ex-officio members will be Paula Szkody (former President) and Colin Scarfe (BCB). Sixteen new members were admitted to C42, giving a total of 360 active members. Regrettably, six members have passed away since the Manchester meeting, including Giuliano Giuricin (Italy), Noel Doughty (New Zealand), Brian Marino (New Zealand), Rozalia Szafraniec (Poland), Peter Wellmann (Germany) and Kenneth Wright (Canada).

\section{Commission Publications}

The Triennial report covering the scientific highlights of close binaries from 2000-2003 is available on the C42 web site and is published in Reports on Astronomy, Vol. XXVa 
(H. Rickman, Editor, ASP), p.277-281. The IBVS is also available through the web site and its triennial report is summarized by Chris Sterken in the DV meeting. There are 150 issues/year. C42 appreciates the work done by the editors of the IBVS in handling these short publications which provide a valuable service to our members. However, it was reported that the number of citations to IBVS is decreasing, so there is a concern whether members are reading the electronic issues now that paper versions are no longer in vogue.

\section{Report on the Bibliography of Close Binaries}

Colin Scarfe took over the chief editorship of The Bibliography of Close Binaries (BCB) from Horst Drechsel beginning with issue 72 in March 2001. We thank Horst for his 6 years of outstanding service and Colin for taking over this job. We also appreciate the work of the other editors H. Drechsel, D. Faulkner, V. Karetnikov, E. Lapasset, C. Maceroni, Y. Nakamura, P. Niarchos, R. Samec, W. Van Hamme and M. Wolf. The most significant development over the past three years is to make BCB available by email or by download from the $\mathrm{C} 42$ website. The editors try to cover all the principal journals, as well as the IAU Circulars and similar publications, but also welcome information about the publication of relevant conference proceedings. They try to share the load as equally as possible among the contributors. Plans for the future include trying to improve the BCB coding system.

One problem mentioned by Colin is the proliferation of catalogues of variable stars, sometimes caused by observation at different wavelengths, and the continued use of catalogue names, even after a standard variable-star name has been assigned, which leads to difficulties of identification. It is very hard to provide an adequate crossreferencing system for so many different catalogues. It is thus increasingly important for authors to use standard names, or at least to refer to them, in publications. To simplify this process in the future, it may be desirable to abandon the old system of variable-star nomenclature in favor of one based purely on position in the sky, as is done in the majority of new catalogues, and in catalogues that resolve binary and multiple systems.

\section{Report on New Recommendations}

Discussion of the new By-Laws led to an affirmation that, while C42 is a large commission of over 350 members, it is an active commission and works well in its present configuration. Since it encompasses many fields within close binaries, it was felt that a large SOC is needed to represent all the areas. There was no support for breaking into smaller groups as it was felt the breadth of topics was good for all members and encouraged members to work with others outside their specific areas. To increase knowledge of members and to identify active members, it was suggested that a members name list be added to the web page, while the email addresses for members should be maintained and checked for current accuracy by the IAU office, as all members of $\mathrm{C} 42$ are also members of other commissions. The IAU representatives from each country should send out emails to determine which members of the IAU are active and wish to remain on the rosters.

\section{Working Group on Accretion Physics}

The WGAP was formed and approved at the IAU XXIV in Manchester. Its current organizers are Paula Szkody, Ed Sion, Mercedes Richards, Martine Mouchet, Sonja Vrielman and Boris Gänsicke. The aim is to focus effort across several disciplines to advance the progress of models and observations. At the Sydney WGAP session, 35 members asked to join and work to define topics for discussion and plan future meetings. 
A web page will be constructed during the next year so topics and arrangements for small discussion groups as well as links to recent papers on accretion can be accessed. Larger meetings will be put together for the XXVI in Prague and a possible followup to the 1989 Paris and the 1996 Australia meetings that brought together ideas on accretion phenomena across disciplines ranging from YSO to CVs to AGN.

\section{Designations of Stellar Companions}

William Hartkopf presented some of the issues that were discussed in detail at the Special Session 3 (A New Classification Scheme for Double Stars) which C42 supported. The major issues of designating the components of binary/multiple stars are presented in the Transactions and a Type C Resolution was proposed. There is general agreement for the WMC system and the current database at USNO that includes all resolved binaries will be expanded to include all other types of binaries. C42 ratified the C Type Resolution as described in the proceedings of Special Session 3. An all-sky catalog will be presented to the SOC a year before IAU XXVI so that a type B resolution can be presented at the Prague General Assembly.

Acknowledgments. I want to thank the members of the Commission and of the Organizing Committee for their help and advice during the last 3 years, especially Ed Guinan who was invaluable in all aspects of handling commission business. I also congratulate the incoming President Alvaro Giménez, Vice President Slavek Rucinski, and the new C42 Organizing Committee members, Ron Hilditch, Birgitta Nordstrom, Ignasi Ribas, Ed Sion and Sonja Vrielman. I also thank Colin Scarfe for his work on the $\mathrm{BCB}$ and his willingness to represent C42 at the Special Session on Naming Conventions. Lastly, I extend a warm welcome to all the new members of $\mathrm{C} 42$ and hope to see them in Prague.

Paula Szkody

President of the Commission 